\title{
Regional review of psychiatric training
}

\author{
Joe Herzberg, Karen Fergus and Elisabeth Paice
}

\begin{abstract}
Aims and method To investigate whether psychiatry training in North Thames met standards set by the Royal College of Psychiatrists and North Thames Deanery. Visits to individual sites to inspect the training programmes and facllities were carried out. A speciality-specific trainee survey (paper questionnaire) was carried out and results from a general trainee satisfaction survey (electronic survey units) are given.

Results We visited all 43 sites. The 207 psychiatry traine completed the speciality-specific questionnaire (response rate 40\%) and 2947 trainees completed the general survey (response rate 71\%) of which 280 responses were from psychiatry trainees. Trainees in psychiatry expressed greater satisfaction with their training than trainees in other specialities. However, we identifled deficiencles in sultabillty of general practitioner posts, safety issues, electroconvulsive therapy supervision, access to multi-disciplinary training and consultant supervision.

Clinical implications Although trainees in psychiatry were generally satisfied with their training, the educational and safety standards set by the Royal College of Psychiatrists and the North Thames Deanery were not always met.
\end{abstract}

North Thames Deanery is responsible for training approximately a sixth of psychiatric trainees in the UK. This paper describes a review of training in the North Thames region, which has chronic problems in recruitment to consultant posts (Kendell \& Pearce, 1997). The quality of training is therefore a high priority for the postgraduate deans.

A semi-structured interview schedule was used by J. H. to record information from 43 site visits, including the interviews with College tutors and training documentation. Chi-squared tests were used to calculate significance.

\section{Surveys of trainees' opinions}

The Deanery carried out two surveys of trainees' opinions in 1996/97. First, a specialityspecific questionnaire based on the Royal College of Psychiatrists recommendations (Joint Committee on Higher Psychiatric Training, 1995; Royal College of Psychiatrists', 1996) was dis- tributed via College tutors and training programme directors. Out of 516 trainees in psychiatry, 205 completed questionnaires (response rate $40 \%$ ) with 167 from basic specialist trainees (response rate $45 \%$ ) and 33 from higher specialist trainees (response rate $23 \%$ ). Two respondents were in academic posts. Second, a general survey of junior doctors in all specialities across North Thames (Paice \& Craig, 1997) was carried out using portable electronic survey units. The general survey covered 58 of the 60 trusts in North Thames. A total of 2947 valid responses were received (response rate $71 \%$ ). Two hundred and eighty trainees (10\%) were in psychiatric posts of whom $138(49 \%)$ were senior house officers and $140(50 \%)$ were registrars, senior or specialist registrars or academic postholders.

\section{Findings}

Site visits

Twenty-nine sites (67\%) offered training posts which were linked to general practice vocational training schemes. Half of these posts offered trainees at least one community-based session. There were no significant differences between the suitability of general practice vocational training schemes posts in teaching hospital trusts and district general hospital/community trusts.

\section{Induction}

Forty-two sites had induction programmes. Twenty-seven $(68 \%)$ of induction programmes were comprehensive and most trainees were satisfied with them (see Table 1). The ratings given to their induction by trainees in psychiatry in the general survey were second only to trainees in accident and emergency departments. Identified deficiencies in the programmes centred on safety issues, tours of casualty and lack of rapid tranquillisation protocols. Six of the 31 sites (19\%) had problems with availability of trained personnel to see psychiatric emergencies with the admitting doctor. These difficulties generally related to a lack of communication with acute trusts responsible departments. The 
Table 1. Ratings of the quality of educational elements of psychiatry posts by trainees in the questionnaire survey

\begin{tabular}{|c|c|c|c|c|}
\hline & $\begin{array}{l}\text { Formal induction } \\
n(\%)\end{array}$ & $\begin{array}{l}\text { Superviston } \\
n(\%)\end{array}$ & $\begin{array}{l}\text { Quality of ectucational programme } \\
n(\%)\end{array}$ & $\begin{array}{l}\text { Quality of exam course } \\
n(\%)\end{array}$ \\
\hline $\begin{array}{l}\text { Very poor } \\
\text { Poor } \\
\text { Average } \\
\text { Good } \\
\text { Very good } \\
\text { Total }\end{array}$ & $\begin{array}{cc}6 & (4) \\
11 & (8) \\
62 & (43) \\
54 & (38) \\
11 & (7) \\
144 & (100)\end{array}$ & $\begin{array}{rr}6 & (3) \\
11 & (6) \\
34 & (19) \\
86 & (47) \\
45 & (25) \\
182 & (100)\end{array}$ & $\begin{array}{rr}2 & (1) \\
18 & (10) \\
58 & (31) \\
90 & (48) \\
18 & (10) \\
186 & (100)\end{array}$ & $\begin{array}{rr}3 & (3) \\
4 & (3) \\
47 & (40) \\
55 & (46) \\
10 & (8) \\
119 & (100)\end{array}$ \\
\hline
\end{tabular}

Table 2. Availability of training meetings and therapy supervision for trainees on the local site

\begin{tabular}{lllllllll}
\hline $\begin{array}{l}\text { Case } \\
\text { conference }\end{array}$ & $\begin{array}{l}\text { Joumal } \\
\text { clubs }\end{array}$ & $\begin{array}{l}\text { Audit } \\
\text { meetings }\end{array}$ & $\begin{array}{l}\text { Other trust } \\
\text { training }\end{array}$ & $\begin{array}{l}\text { Dynamic } \\
\text { poychotherapy }\end{array}$ & CAT & CBT & $\begin{array}{l}\text { Family } \\
\text { therapy }\end{array}$ & $\begin{array}{l}\text { Sexuall } \\
\text { problems }\end{array}$ \\
\hline 39 & 38 & 37 & 34 & 37 & 10 & 39 & 31 & 12 \\
$(93 \%)$ & $(91 \%)$ & $(86 \%)$ & $(79 \%)$ & $(88 \%)$ & $(23 \%)$ & $(91 \%)$ & $(72 \%)$ & $(29 \%)$ \\
\hline
\end{tabular}

CAT, cognitive analytical psychotherapy; CBT, cognitive-behavioural therapy.

findings echo those of a recent paper (Chubb. 1997).

\section{Electroconvulsive therapy}

Electroconvulsive therapy (ECT) was routinely given on 29 sites. In four (14\%) the initial teaching session was delegated to a nonconsultant. In $15(52 \%)$ only the first treatment session was supervised by a consultant and thereafter trainees were supervised by other trainees, general specialist registrars. Many consultants responsible for the supervision of ECT had not been on College updating courses and on seven sites (24\%), machines, were used which were not on the recent College approved list. These findings echo those of the College survey (Duffett \& Lelliott, 1997).

\section{Training meetings and supervision}

The availability of training meetings and supervision in various modalities of psychotherapy is shown in Table 2 . Only $24(60 \%)$ of case conferences and eight journal clubs (21\%) were attended by non-medical professionals, but approximately three-quarters of the audit meetings were multi-disciplinary. Trainees on six (14\%) sites did not have access to audit programmes. Attendance by trainees at the local programme was unsatisfactory on six (14\%) sites due to service pressure and only $15(35 \%)$ sites had arrangements to ensure that trainees were 'bleeper-free' for the training programmes. College tutors were more satisfied with the quality of MRCPsych courses than MSc courses, but trainees were generally satisfied with the local programmes and MRCPsych courses (Table 1).
The hours of formal (organised, timetabled) educational activities attended were significantly higher in psychiatry than in all other specialities in the general survey. Nonetheless, in the general survey, $50(18 \%)$ trainees reported attending less than the three hours required by the postgraduate deans' educational contract. One hundred and fifty-five trainees (78\%) in the specialityspecific survey reported having regular weekly supervision, and in the general survey trainees rated consultant supervision in psychiatry higher than in all other specialities except accident and emergency. The general survey revealed that psychiatric trainees were more likely to have discussed their educational objectives with their consultant at the beginning of the post and subsequently discussed their progress than trainees in all other specialities.

\section{Research and study leave}

Forty-three sites (relating to 32 NHS trusts and one private provider) were visited. Of these 43 only four (9\%) had no academic links. Library facilities were visited and were generally satisfactory, although one site had no library. Thirtythree $(77 \%)$ had access to online literature search facilities. Local support for research was available on 35 sites (81\%). Trainees were significantly more likely to have published research projects when working in trusts closely associated with teaching hospitals than in trusts without academic affiliation $\left(\chi^{2}=4.19, P=0.04\right)$. College tutors were asked about the arrangements for study leave within their trust. Four tutors (9\%) reported problems in obtaining sufficient funds or satisfactory service cover for their trainees. 


\section{Hours and conditions of work}

The general survey revealed that posts in psychiatry were more likely to fulfil the requirements of the 'New Deal' on junior doctors' hours than in any other speciality, with less arduous rotas (mean 1:7 psychiatry, 1:5 others; $P<0.001$ ) and the expectation of continuous uninterrupted rest during a 32-hour duty period was better in psychiatry (mean 5.8 hours psychiatry, 4.9 others; $P<0.001$ ). However, the hands-on experience acquired in psychiatry posts was rated as highly as in most other specialities. Accommodation and the availability of hot food out of hours were criticised in common with other specialities.

\section{Discussion}

Using the three-pronged approach of site visit, speciality-specific paper questionnaire and comparative data from a general survey of trainees from all specialities, we found that psychiatric trainees were mostly content with their training. Compared with trainees in other specialities, they found both the workload and the educational framework of their posts relatively satisfactory. However, some aspects of education could be improved. The North Thames Deanery standard of three hours of formal education attended each week was not universally attained. The multi-disciplinary aspect of many training programmes could be improved. Nearly a quarter of all trainees were not receiving regular weekly supervision: a cause for concern given the emphasis that the College places on this educational standard. The structure of many general practice vocational training scheme posts seemed directed to secondary care services rather than general practice training and there was a lack of adequate community-based experience, despite the fact that general practitioners need mental health training (Kerwick et al, 1997). We were particularly concerned about safety issues. Service arrangements and induction in these areas were deficient in some trusts.
Supervision arrangements for ECT were often inadequate, and we hope the move by the College to accredit ECT clinics will improve standards over time. Despite the relative satisfaction of trainees with their training, there is still room for considerable improvement in the quality of training in psychiatry in North Thames.

\section{Acknowledgements}

We thank all the trainees, College tutors and programme directors who assisted with these surveys.

\section{References}

ChUвв, H. (1997) Safety awareness among junior psychiatrists and provision for their safety in the workplace. Psychiatric Bulletin, 21, 80-83.

DUFFET,, R. \& Leunor, P. (1997) Junior doctors' training in the theory and the practice of electroconvulstive therapy. Psychiatric Bulletin, 21, 563-565.

JoINT COMmitTeE ON Higher PSYChIATRIC TRAINING (1995) Joint Committee on Higher Psychiatric Training Handbook (7th edn). Occastonal Paper 27. London: Royal College of Psychiatrists.

KENDELL, R. E. \& PEARCE, A. (1997) Consultant psychiatrists who retired prematurely in 1995 and 1996. Psychiatric Bulletin, 21, 741-745.

KERWCK, S. JONES, R. MANN, A., et al (1997) Mental health care training priorities in general practice. British Joumal of General Practice. 47, 225-227.

PAICE, E. \& CRAIG. G. (1997) North Thames Trainees Point of View Survey. London: Thames Postgraduate Medical and Dental Education.

Royal COLEGE OF PsychIATRIST (1996) Statement on Approval of Training Schemes for Basic Specialist Training for the MRCPsych. London: Royal College of Psychiatrists.

*Joe Herzberg, Associate Dean-Mental Health: Karen Fergus, Assistant to the Associate Dean Mental Health; Elisabeth Paice, Dean/Director, Thames Postgraduate Medical and Dental Education, 33 Millman Street, London WC1N 3EJ

*Correspondence 